\title{
Venlafaxine induced hepatotoxicity in a carcinoma of breast survivor with co-morbid depression
}

\author{
Rajnish Raj ${ }^{1 *}$, Nisha Bhagat ${ }^{2}$
}

${ }^{1}$ Department of Psychiatry,

${ }^{2}$ Department of Obstetrics and Gynecology, Government Medical College and Rajindra Hospital, Patiala 147001, Punjab, India

Received: 23 July 2017 Accepted: 22 August 2017

\section{*Correspondence to: \\ Dr. Rajnish Raj, \\ Email: drrajnish_raj@ yahoo.com}

Copyright: (C) the author(s), publisher and licensee Medip Academy. This is an openaccess article distributed under the terms of the Creative Commons Attribution NonCommercial License, which permits unrestricted noncommercial use, distribution, and reproduction in any medium, provided the original work is properly cited.

\begin{abstract}
Drug Induced Liver Injury (DILI) is one of the leading causes of liver damage worldwide and raises concerns about its prescription in lieu of the limited drug options available for the depression. Venlafaxine (VEN) is an antidepressant with dual neurotransmitter receptor modulations i.e., serotonin and norepinephrine reuptake inhibitor (SNRI) and having an additional benefit in management of vasomotor symptoms especially in menopausal patients where hormone replacement therapy (HRT) is contraindicated. VEN induced hepatotoxicity have been reported to occur in less than $1 \%$ of patients. Until now, less than 11 cases of VEN-related liver injuries have been reported in literature. We hereby, report a rare case of VEN induced liver injury in a 40-year-old breast cancer survivor with co-morbid depression.
\end{abstract}

Keywords: Drug induced liver injury, Depression, Hot flashes, Venlafaxine

\section{INTRODUCTION}

Vasomotor symptoms are debilitating in patients who develop chemotherapy induced menopause in carcinoma of breast where HRT is contraindicated. Preliminary data have suggested that antidepressant like VEN is an effective non-hormonal treatment for management of hot flashes and other vasomotor symptoms. ${ }^{1}$ VEN inhibits the reuptake of both 5-hydoxytryptophan (5-HT) and noradrenaline (NA), and only a weak inhibition of dopamine uptake, following oral absorption, peak plasma concentration is achieved after about 2 hours. $^{2}$ It has large volume distribution $6.8 \mathrm{~L} / \mathrm{kg}$ after administration of $75 \mathrm{mg}$,
3 times daily for 3 days, and low plasma-protein binding $30 \%$, which suggests a wide tissue distribution. ${ }^{3}$ VEN undergoes extensive first-pass metabolism and less than $5 \%$ of the parent drug is excreted in the urine. The majority of drug is metabolized in liver to a major metabolite, Odemethyvenlafaxine, and two minor, less active metabolites, N-demethyvenlafaxine and N, Odidemethylvenlafaxine. It is metabolized by CYP 2D6 isoenzyme of cytochrome P450. ${ }^{4}$

VEN induced hepatotoxicity is rare but a life threatening adverse effect and reported in $0.4 \%$ of patients. ${ }^{5}$ The mechanism for liver injury due to VEN is either immunoallergic in nature, metabolic or due to its intermediate 
metabolites. The liver function tests (LFT) e.g., serum alanine aminotransferase (ALT) values of more than three times of upper limit of normal (ULN) or $50 \%$ decrease in levels of liver enzymes following withdrawal of the suspected drug, is highly suggestive of DILI. ${ }^{6} \mathrm{We}$ hereby, report case of VEN induced hepatotoxicity in a carcinoma of breast survivor with co-morbid depression that subsided after withdrawal of the drug.

\section{CASE REPORT}

A 40-year-old female presented in Out Patient Department (OPD) of Obstetrics and Gynecology, Rajindra Hospital, Patiala with complaints of hot flashes, palpitation, sweating, tachycardia, jitteriness, dizziness and insomnia; there were 6-8 episodes per day with sadness of mood for the last three months. The symptoms were gradual in onset, without psychosocial stressors and progressive in nature, distressing and interfering in her day to day activities. She underwent right mastectomy due to breast carcinoma 7 years ago followed by chemotherapy, which resulted in premature menopause. There was no history of any hopelessness, worthlessness and helplessness, suicidal ideation, plan or attempt and guilt. These symptoms were not attributed to the physiological effect of substance e.g., chemotherapy as patient was not on any regimen for the last six years. To delineate the burden of psychiatric morbidity in carcinoma breast survivor patient psychiatric consultation was sought for the aforementioned symptoms. On mental state examination, speech was low in volume, coming at decreased rate and rhythm, her mood was sad, affect appropriate to the mood content; thought process, content, perception, Judgment and insight to the illness were normal. There was a possibility of co-morbid psychopathology, as the assessment on Diagnostic and Statistical Manual of Mental Disorder (DSM-5) revealed a clinical diagnosis of 296.21 (F32.0) Single Major depressive disorder (MDD) with specifiers: of mild degree in severity and anxious distress type in nature. ${ }^{7}$ She had HAM-D score of 12 indicative of mild depression and HAM-A score of 17 , indicating mild anxiety with CGI-S score of $4 .^{8-10}$ Therefore, in consultation with psychiatrist, she was started with low dose VEN of $37.5 \mathrm{mg}$ per day for one week with gradual increase to $75 \mathrm{mg}$ per day on second week. These medicines were continued for 3 months.

However, she reported back in OPD after 3 months with complaints of loss of appetite, nausea, occasional right upper quadrant pain and loss of weight, though was relieved-off her vasomotor but depressive symptoms worsened and had HAM-D score of 14, indicative of moderate depression with CGI-I score of 5, indicating minimal worsening. So, she was referred back to psychiatry department for re-evaluation and further management. General physical examination (GPE) showed that she was oriented to time, place and person, moderately built and moderately nourished with BMI of 26. She was vegetarian and non-alcoholic with no family history of liver disease. Vitals were normal. Laboratory investigations revealed serum bilirubin $0.7 \mathrm{mg} \%$, aspartate aminotransferase (AST) levels 179IU/L (ULN, 40IU/L), alanine aminotransferase level (ALT) 355IU /L (ULN, 40IU/L) and Serum alkanine phosphatase (ALP) 125IU/L (ULN, 141IU/L), Human-immune deficiency virus (HIV), Hepatitis-C (HCV), Hepatitis-B were negative. Total and differential serum proteins (TSP/DSP) were within normal limits. Ultrasound abdomen showed liver measure of 17.5 $\mathrm{cm}$, bright in echo-pattern with signs of Grade-1 fatty infiltration and normal in shape. Fibroscan revealed median stiffness of $8.6 \mathrm{Kpa}$ (normal values less than $6 \mathrm{Kpa}$ ), interquartile range (IQR): $2.2 \mathrm{Kpa}$ and IQR/ med: $26 \%$.

As there was no other cause for raised liver enzymes and Naranjo's adverse drug reaction probability scale (NADRPS) revealed score of 8 , which was consistent with probable adverse drug reaction. ${ }^{11}$ Thus, VEN induced hepatotoxicity was made. Drug was immediately withdrawn and replaced with escitalopram $10 \mathrm{mg}$ per day. On subsequent follow-up for another three weeks, her LFT levels became normal. Re-challenge drug test was not done due to the fear of fulminant hepatic failure. She was relieved of her symptoms as HAM-D, HAM-A and CGI-I scores of 7, 8 and 1, suggested very much improvement.

\section{DISCUSSION}

Antidepressant related hepatic injury is a diagnosis of exclusion; it can mimic almost all known liver diseases (viral hepatitis, alcoholic liver disease, non-alcoholic fatty liver disease, autoimmune hepatitis, metabolic diseases, biliary tract obstruction, hepatic ischemia, vascular obstruction) and consequently, diagnosed by ruling out all other possible causes. ${ }^{12}$

VEN is a newer antidepressant and serotonin and norepinephrine reuptake inhibitor (SNRI) with a clinically proven role in treatment of vasomotor symptoms in breast cancer survivors where HRT is contraindicated. ${ }^{13}$ It is metabolized in liver by cytochrome P450 enzymatic system. Common side effects are drowsiness, dyspepsia, nausea, headache, increased appetite, increased sweating and sexual dysfunction. Hepatocellular injuries concomitant with elevated AST and ALT enzyme level have been reported even in patients treated with low doses of VEN. ${ }^{14,15}$ It has been associated with cholestatic as well as hepatocellular liver damage in patients without a preceding history of liver dysfunction or marked alcohol use. ${ }^{16}$ Stadlmann et al, reviewed 10 cases of VEN-related liver injury and reported a 39-year-old woman who developed VEN related cholestatic hepatitis, these symptoms resolved after cessation of VEN and administration of corticosteroids. ${ }^{17}$ Detry et al, reported a case of a 48-year-old depressed patient treated with VEN and trazodone therapy who manifested fulminant hepatic failure with a further liver transplantation after developing toxic liver injury, jaundice and encephalopathy. ${ }^{18}$ In our case, hepatocellular injury was probably due to VEN as indicated by increase in the serum levels of AST and ALT with a normal level. 
Clinical presentation of hepatotoxicity ranges from isolated increase in liver enzyme levels to non-specific symptoms such as asthenia, fatigue, anorexia, nausea, vomiting and upper right abdominal pain and also to more specific symptoms such as jaundice, dark urine or pale stools, acute liver failure and even death. Symptoms may appear within days to 6 months after the initiation of drug. However, in most of the cases patient is asymptomatic and only an alteration in the liver function tests raises the suspicion of DILI. The early diagnosis and immediate withdrawal of the offending drug and replacement by other safer and effective alternative is required. Spontaneous resolution occurs within 4 weeks in most of the patients. In our case, the offending drug was replaced with escitalopram that is also effective for the management of depression and vasomotor symptoms and well tolerated. ${ }^{19}$

\section{CONCLUSION}

Although an infrequent event, yet VEN induced liver injury may be irreversible and life threatening. High index of suspicion is required to diagnose as it is the diagnosis of exclusion. It is suggested that in patients, who are on VEN, the baseline laboratory investigation and periodic followup of aminotransferases enzymatic assay (AST, ALT and ALP) surveillance may be used in routine for an early detection of hepatic injury as prompt discontinuation of drug in initial stage reverses hepatocellular damage. Furthermore, the results of antidepressant induced liver toxicity in all phases of clinical trials should be made available, reported and published.

Funding: No funding sources Conflict of interest: None declared

Ethical approval: Not required

\section{REFERENCES}

1. Loprinzi CL, Kugler JW, Sloan JA, Mailliard JA, LaVasseur BI, Barton DL, et al. Venlafaxine in management of hot flashes in survivors of breast cancer: a randomised controlled trial. Lancet. 2000;356:2059-63.

2. Holliday SM, Benfield P. Venlafaxine: a review of its pharmacology and therapeutic potential in depression. Drugs. 1995;49:280-94.

3. Klamerus KJ, Moloney K, Rudolph RL, Sisenwine SF, Jusko WJ, Chiang ST. Introduction of a composite parameter to the pharmacokinetics of venlafaxine and its active O-desmethyl metabolite. The Journal of Clinical Pharmacology. 1992 Aug 1;32(8):716-24.

4. Otton SV, Ball SE, Cheung SW, Inaba T, Rudolph RL, Sellers EM. Venlafaxine oxidation in vitro is catalysed by CYP2D6. Clin Pharmacol. 1996;41:149-56.

5. Rudolph RL, Derivan AT. The safety and tolerability of venlafaxine hydrochloride: Analysis of the clinical trials database. J Clin Psychopharmacol. 1996;16:54S9S.
6. Verma S, Kaplowitz N. Diagnosis, management, and prevention of drug-induced liver injury. Gut. 2009;58:1555-64.

7. American Psychiatric Association. Diagnostic and Statistical Manual of Mental Disorders ( $5^{\text {th }}$ Edn) (DSM-5). Arlington VA: American Psychiatric Association; 2013:123-154.

8. Hamilton M. A rating scale for depression. J Neurol Neurosurg Psychiatry. 1960;23:56-62.

9. Hamilton M. The assessment of anxiety states by rating. Br J Med Psychol. 1959;32:50-5.

10. Beneke M, Rasmus W. Clinical global impressions (ECDEU): some critical comments. Pharmacopsychiatry. 1992;25:171-6.

11. Naranjo CA, Busto U, Sellers EM, Sander P, Ruiz I, Roberts EA, et al. A method for estimating the probability of adverse drug reactions. Clin Pharmacol Ther. 1981;30:239-45.

12. Aithal GP, Watkins PB, Andrade RJ, Larrey D, Molokhia M, Takikawa H, et al. Case definition and phenotype standardization in drug-induced liver injury. Clin Pharmacol Ther. 2011;89:806-15.

13. Bordeleau L, Pritchard KI, Loprinzi CL, Ennis M, Jugovic O, Warr D, et al. Multicenter, randomized, cross-over clinical trial of venlafaxine versus gabapentin for the management of hot flashes in breast cancer survivors. J Clin Oncol. 2010;28:5147-52.

14. Sencan I, Sahin I, Ozcetin A. Low-dose venlafaxineassociated liver toxicity in chronic hepatitis. Ann Pharmacother. 2004;38(2):352-3.

15. Phillips BB, Digmann RR, Beck MG. Hepatitis associated with low-dose venlafaxine for postmenopausal vasomotor symptoms. Ann Pharmacother. 2006;40(2):323-7.

16. Cardona X, Avila A, Castellanos P. Venlafaxineassociated hepatitis. Ann Intern Med. 2000;132(5):417.

17. Detry O, Delwaide J, De Roover A, Hans MF, Delbouille MH, Monard J, et al. Fulminant hepatic failure induced by venlafaxine and trazodone therapy: A case report. Transplant Proc. 2009;41(8):3435-6.

18. Stadlmann S, Portmann S, Tschopp S, Terracciano LM. Venlafaxine-induced cholestatic hepatitis: case report and review of literature. Am J Surg Pathol. 2012;36(11):1724-8.

19. Freeman EW1, Guthrie KA, Caan B, Sternfeld B, Cohen LS, Joffe H, et al. Efficacy of Escitalopram for Hot Flashes in Healthy Menopausal Women: A Randomized Controlled Trial. JAMA: J Am Med Assoc. 2011;305(3):267-74.

Cite this article as: Rajnish $\mathrm{R}$, Bhagat $\mathrm{N}$.

Venlafaxine induced hepatotoxicity in a carcinoma of breast survivor with co-morbid depression. Int $\mathbf{J}$ Basic Clin Pharmacol 2017;6:2534-6. 